\title{
Mineralogical Study of Historical Bricks of Patan, Nepal Using XRD and FTIR Analysis
}

\author{
Suman L. Shrestha* \\ Department of Chemistry, Patan Multiple Campus, Tribhuvan University, Nepal \\ Institute of Science and Technology, Tribhuvan University, Nepal
}

*Corresponding Author: Suman L. Shrestha, Department of Chemistry, Patan Multiple Campus, Tribhuvan University, Nepal, Institute of Science and Technology, Tribhuvan University, Nepal

\begin{abstract}
Present study is focused to study chemico-mineralogical characterization of a century old three brick samples collected from Patan city of Kathmandu valley, Nepal using X-ray powder diffraction (XRD) and Fourier transform infrared (FTIR) spectroscopic techniques. The mineralogical phases existed in all three clay brick samples used to analyze in this study by XRD-patterns are found to be of quartz, cristobalite, mullite, feldspars and different clay minerals, mostly of mica minerals from the analysis of XRD patterns. The presence of the mullite phase in all three fired clay bricks was fired at high temperature of $1100^{\circ} \mathrm{C}$ or $\mathrm{more}$ from both the XRD and FTIR analyses.
\end{abstract}

Keywords: Ceramic brick, XRD, FTIR, Quartz, Mullite, Feldspars.

\section{INTRODUCTION}

Bricks, a prevalent building material, are used extensively in the construction industry. India and the United States, for example, consume 20 billion and 9 billion bricks each year, respectively [1]; [2]. The annual worldwide production of bricks is about 1.391 trillion units and demand for bricks is expected to continue rising [3]. With increasing demands of the construction industry, bricks quality and cost become more important day by day. Clay bricks, made from clays, silica, fluxes, coloring and other raw materials are one of the simplest examples of the traditional ceramic body. They are prepared by grinding, sieving, mixing, moistening, shaped by pressing, casting or other processes, usually at room temperature. Then they are dried and subsequently fired at a high temperature. Bricks are widely used in buildings, foundation walls and boundary. Depending on the degree of firing at high temperature, the chemical/mineralogical, physico-chemical, mechanical and thermal properties of the ceramic bodies are varied. All these properties of the clay ceramic bricks are interrelated to each other.

Different clay minerals are the principal raw materials which have a large effect on their technological properties for manufacturing various clay bricks [4]. Content of water and dispersion of the solid phase of the clays used for the production of the clay bricks should be optimized taking into account subsequent drying and sintering to ensure the maximally high parameters of the brick product. The chemical composition of the clay raw materials is one of the main indicators for selection of a component for the final mixture. $\mathrm{Al}_{2} \mathrm{O}_{3}$ has the largest effect on the properties of ceramic articles. As the $\mathrm{Al}_{2} \mathrm{O}_{3}$ content increases the refractoriness and mechanical strength of the material increases. On the other hand, $\mathrm{SiO}_{2}$ decreases the shrinkage and it also decreases refractoriness of the ceramic products. Varieties of feldspars, sodium, potassium, calcium, magnesium, iron and titanium oxides are strong fluxes, which decrease the viscosity of the liquid phase of the ceramic products. High $\mathrm{Fe}_{2} \mathrm{O}_{3}$ and $\mathrm{TiO}_{2}$ content of clay reduce the quality of the product but offer higher plasticity and mechanical strength.

On the other hand, the amounts of fluxing oxides show a direct correlation with bulk density and an inverse relation with water absorption of the fired clay ceramic bodies. Important source of these fluxing oxides are different feldspars and the presence of high concentration of fluxing components in the clay ceramic body permit a lowering of its firing/sintering temperature [5]; [6]; [7]; [8]. It was investigated the effect of the particle size distribution of feldspar on the formation of pores in the 
green compact and the final clay ceramic products [5]. In addition, the porosity also affects their mechanical properties. It was reported that the Young's modulus decreased with increasing porosity [6], and at equivalent porosities, specimens with small pores were found to have a higher Young's modulus than specimens with large pores [7]. It is equally understandable that porosity of clay ceramic bodies is associated with inferior quality, because high porosity and surface pores create the same problems in mechanical properties of the bodies. It is also important to acknowledge that inferior ceramic tile is not one that simply has high porosity, but the number and size of surface pores is equally important [8]. However, such type of chemico-mineralogical and sintering properties of the fired ceramic bodies available in local market of Nepal is reported very few in the scientific community of Nepal [9]; [10]; [11]. Considering these facts behind the quality of old clay bricks to correlate their mechanical properties with chemico-mineralogical composition, the present research work is focused to characterize the mineralogy and phases present in the collected three different a century old bricks used as a local house construction material in Patan city of Kathmandu valley, Nepal using techniques of XRD and FTIR analysis.

\section{Materials AND Methods}

\subsection{Sampling Site and Sample Preparation}

Three clay brick samples were collected from three buildings (more than hundred years old) of Patan, an ancient city of Nepal, to characterize their chemical and mineralogy. Small broken pieces of the brittle bricks potsherds without glaze were thoroughly hand grounded to fine powder in agate mortar as shown schematically in Fig. 1.

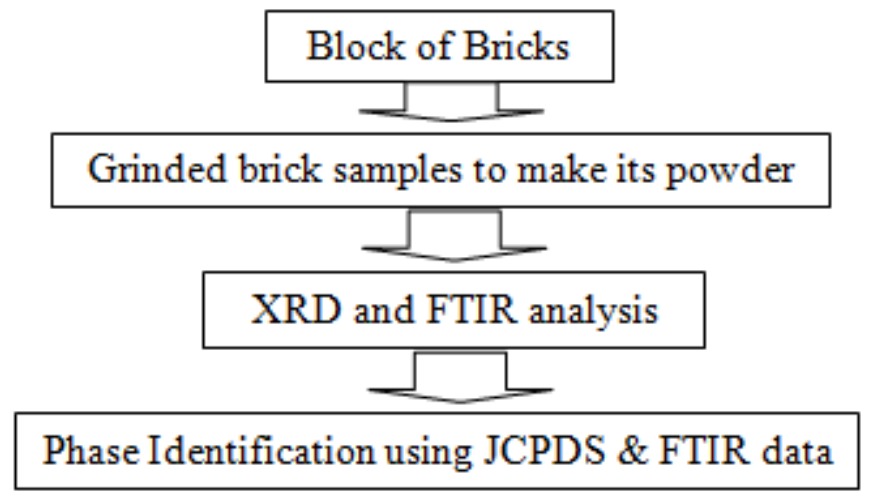

Figure1. Schematic representation of preparation of the sample specimens for recording XRD and FTIR spectra of the ceramics bricks

\subsection{XRD and FTIR Analysis of Bricks}

Phase and chemico-mineralogical characterization of the clay ceramic brick samples was carried out at Nepal Academy of Science and Technology (NAST), Khumaltar, Lalitpur using X-ray diffraction (XRD) analysis on a D8 Advanced Diffractometer (Bruker, Germany) with $\mathrm{Cu} \mathrm{K} \alpha$ radiation $(\lambda=$ $0.15418 \mathrm{~nm}$ ) at a scanning speed of $2 \%$ minute in $2 \theta$ mode between $20^{\circ}-80^{\circ}$. Major and minor phases present in ceramic bodies of bricks were identified from their basal spacing (d-spacing) values using JCPDS files as a reference. The samples were loaded in a sample holder in a randomly orientated way to minimize preferred orientations of clay minerals. Characterization of the brick specimens were qualitatively determined using Fourier Transform Infrared Spectrophotometer (FTIR) A217053 and spectra was recorded at Nepal Academy of Science and Technology (NAST) using KBr pellet.

\section{RESULTS AND DISCUSSION}

\subsection{Mineralogical Analysis of Clay Bricks}

The mineralogical analysis of three fired clay bricks were carried out using both techniques of powder X-ray diffraction (XRD) and Fourier transform infrared spectroscopic (FTIR) in the present research work.

\subsubsection{XRD Patterns of Clay Bricks}

XRD technique is one of the mostly used methods to identify different minerals and compounds present in fired clay bricks [12]. Qualitative identification of the phases present in the clay bricks by XRD patterns is relatively easy, although several factors makes complication for accurate 
identification of the phases present in them [13]. Phases developed during the firing step of the clay ceramic bodies are generally correlated with their physico-chemical and mechanical properties [14]. On the other hand, mineralogy study of the clay-based ceramic bodies is one of the widely accepted tools for the approximate determination of firing temperatures. In this context, present work was focused to identify the phase compositions of three collected clay bricks from Patan city of Kathmandu valley using XRD patterns and the results are shown in Figs 2-4. Crystalline phases present in the analyzed three fired ceramic brick samples were identified mainly of quartz, feldspars, cristobalite, biotite, muscovite and mullite with the help of the corresponding JCPDS (Joint Committee on Powder Diffraction Standards) database files [15].

The mineralogical phases existed in all three clay brick samples used to analyze in this study by XRDpatterns are almost same, i. e., quartz, cristobalite, mullite, feldspars and different clay minerals, mostly of mica minerals. However, the mullite phase in samples Brick-P2 and Brick-P3 is more clearly observed than the Brick-P1 sample. This result indicates that the firing temperature of these ceramic bricks should not be same. It is assumed that the firing temperature used to produce the century old brick samples of Brick-P2 and Brick-P3 should be higher than that of the brick sample of Brick-P1. It was reported that a spinel-type phase was appeared in ceramic bodies after fired at above $900^{\circ} \mathrm{C}$ and the spinel was lost and mullite crystals begin to develop at about $1050^{\circ} \mathrm{C}$ and the spineltype phase completely disappears with increasing firing to $1100^{\circ} \mathrm{C}$ and the mullite phase becomes very pronounced [16]. Consequently, it can be said that the presence of the mullite phase instead of the spinel-type phase in all three fired clay bricks analyzed in this study were fired at high temperature of $1100^{\circ} \mathrm{C}$ and high. On the other hand, as shown in Figs 2-4, the XRD patterns of the muscovite and biotite type clay minerals is clearly observed in the clay raw minerals used to produced the fired brick samples used to analyze in this study. This reflects that the raw materials used to produce these brick samples are not different, but the firing temperature should be different. It is meaningful for mentioning here that the mullite phase was found to be formed after the breakdown of the muscovite mineral by TEM study [17] and the similar results were reported by other researchers [18]; [19].

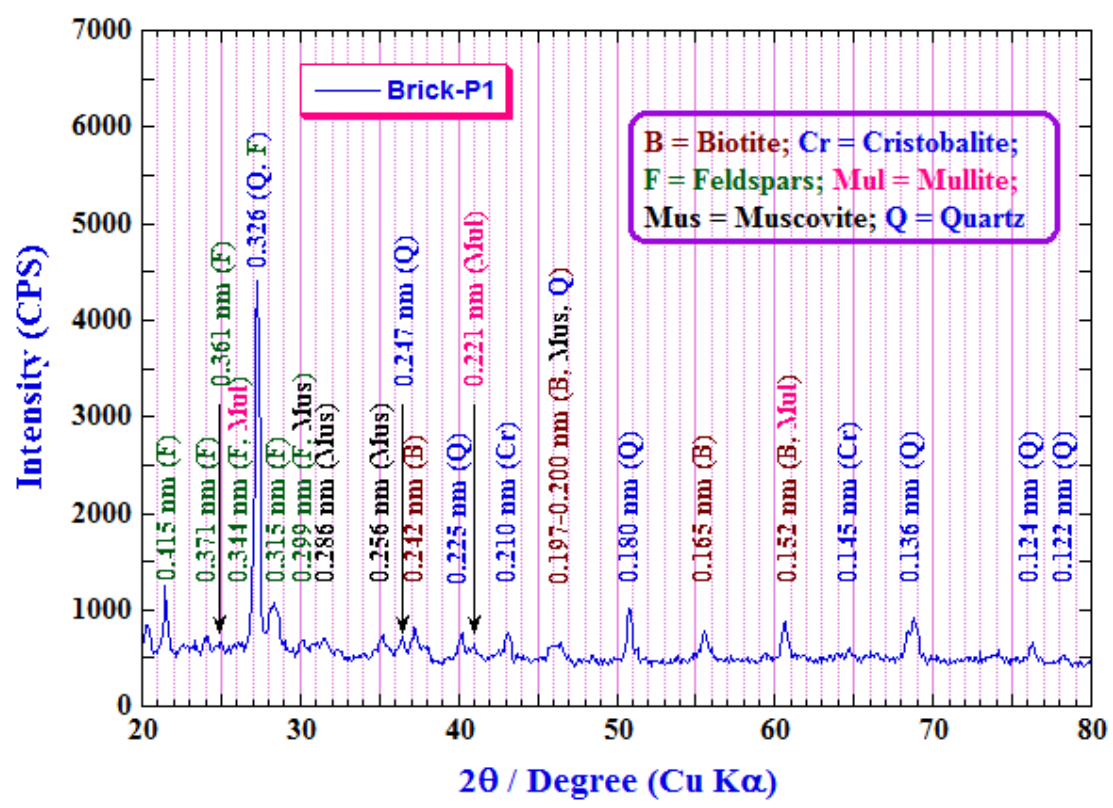

Figure2. XRD patterns of clay brick-PI

Due to the fact that the ceramic systems are non-equilibrium systems, different phases develop as the heating temperature varies both in time duration and degree. Consequently, it becomes difficult to predict the exact final phases of the end products of the fired ceramic bodies like bricks. The main constituents of the clay bodies are mullite and quartz which are held together by forming glass phase (initiated from the melting of feldspar) when ceramic raw materials are fired at high temperature. Due to the presence of impurities in some raw materials of the ceramic bodies, attached minor phases inevitably develop that had negative effects on the mechanical properties. In general, the mechanical properties of the fired clay bodies are worsening in presence of undesired phases like calcite and dolomite observed in XRD patterns of the fired clay bricks [20]; [21]; [22]; [23]. However, there is no sign of the presence of calcite and dolomite phases in the presently analyzed three brick samples and 
presence of mullite and residual forms of quart and cristobite indicated that these a century old brick samples should have good mechanical and physico-sintering properties. It is considered that the mechanical strength of the ceramic bodies can attribute to the formation of mullite, residual quartz content and its particle size, and amount of glassy phases present in it [24]; [25].

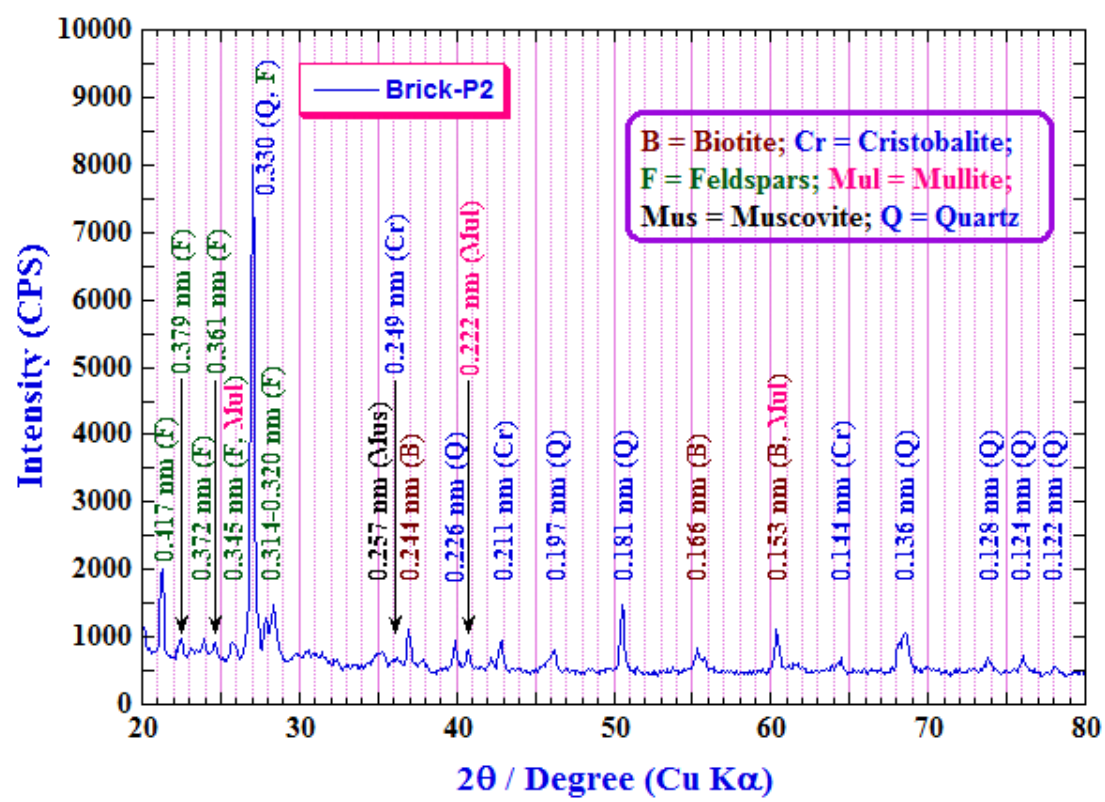

Figure3. XRD patterns of clay brick-P2

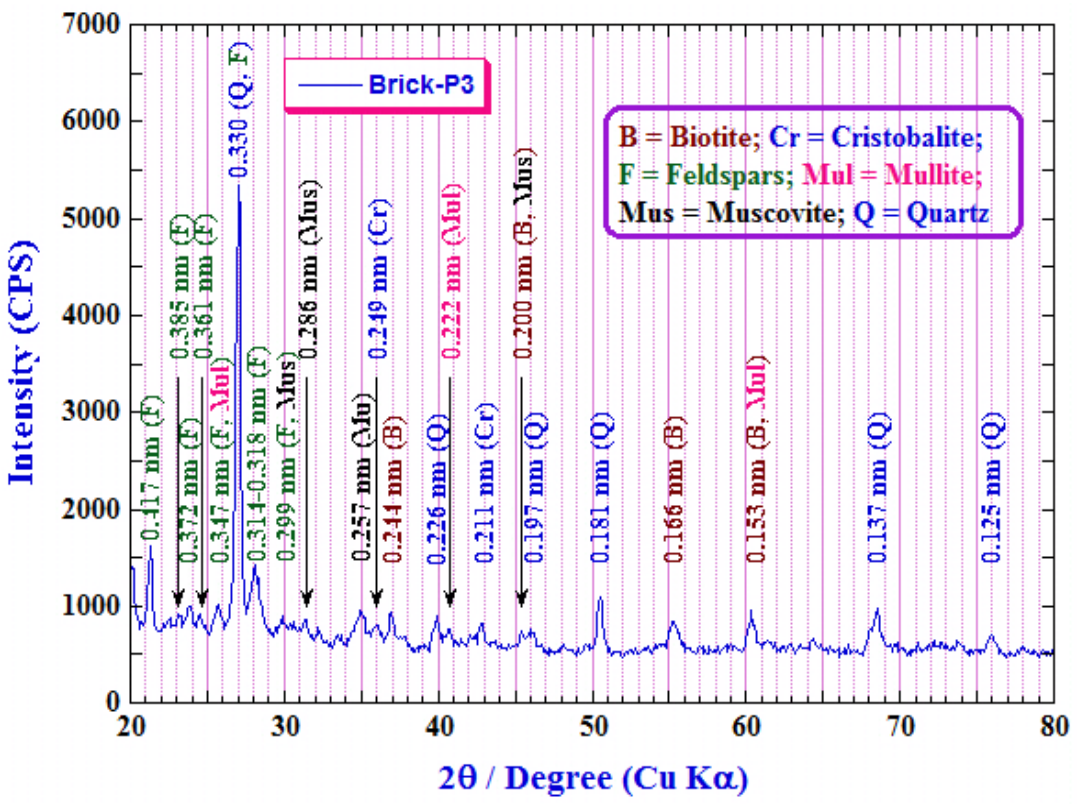

Figure4. XRD patterns of clay brick-P3

\subsubsection{FTIR Spectra Analysis of Clay Bricks}

FTIR spectra of the powder form of the collected three clay bricks of Patan city house were taken to identify their functional groups and their FTIR spectra are shown in Figs 5-7. A broad absorption peak in the range of $3441-3447 \mathrm{~cm}^{-1}$ is observed more clearly in the FTIR spectra of all the analyzed three fired clay brick samples used in this study, mostly due to $\mathrm{H}-\mathrm{O}-\mathrm{H}$ vibrations of adsorbed water. It is meaningful to mention here that it was reported a broad absorption peak of water at $3435 \mathrm{~cm}^{-1}$ due to the overlapping asymmetric $v 3$ and symmetric $v 1(\mathrm{H}-\mathrm{O}-\mathrm{H})$ stretching vibrations of hydrogenbonded water molecule [26]. On the other hand, the FTIR absorption peaks between 3750 and 3500 $\mathrm{cm}^{-1}$ are diminished and only a broad peak in the range of $3441-3447 \mathrm{~cm}^{-1}$ is observed for fired clay brick samples of Brick-P1 and Brick-P3 except the Brick-P2 sample as shown in Figs 5-7. A very weak peak at around $3615 \mathrm{~cm}^{-1}$ is observed for the Brick-P2 sample in addition to the very broad absorption peak at $3443 \mathrm{~cm}^{-1}$ as shown in Fig. 5. It was reported that a broad peak near $3420-3480$ 
$\mathrm{cm}^{-1}$ represents to the $\mathrm{OH}$ stretching vibration along with a weak and medium absorption band at $1620-1650 \mathrm{~cm}^{-1}$ is typical absorbance band of adsorbed water molecule [27]. Hence, the broad band at $3441-3447 \mathrm{~cm}^{-1}$ for the aforementioned three clay brick samples is attributed to $\mathrm{OH}$ stretching vibration of hydroxide in different brick samples. It is meaningful for mentioning here that A1-A1 band between 3617 and $3624 \mathrm{~cm}^{-1}$ is common for the spectra of all Al-containing pyrophyllite clay samples. It was reported that inner hydroxyl groups, lying between the tetrahedral and octahedral sheets of any clay minerals gave an absorption peak near $3620 \mathrm{~cm}^{-1}$ [28]; [29].

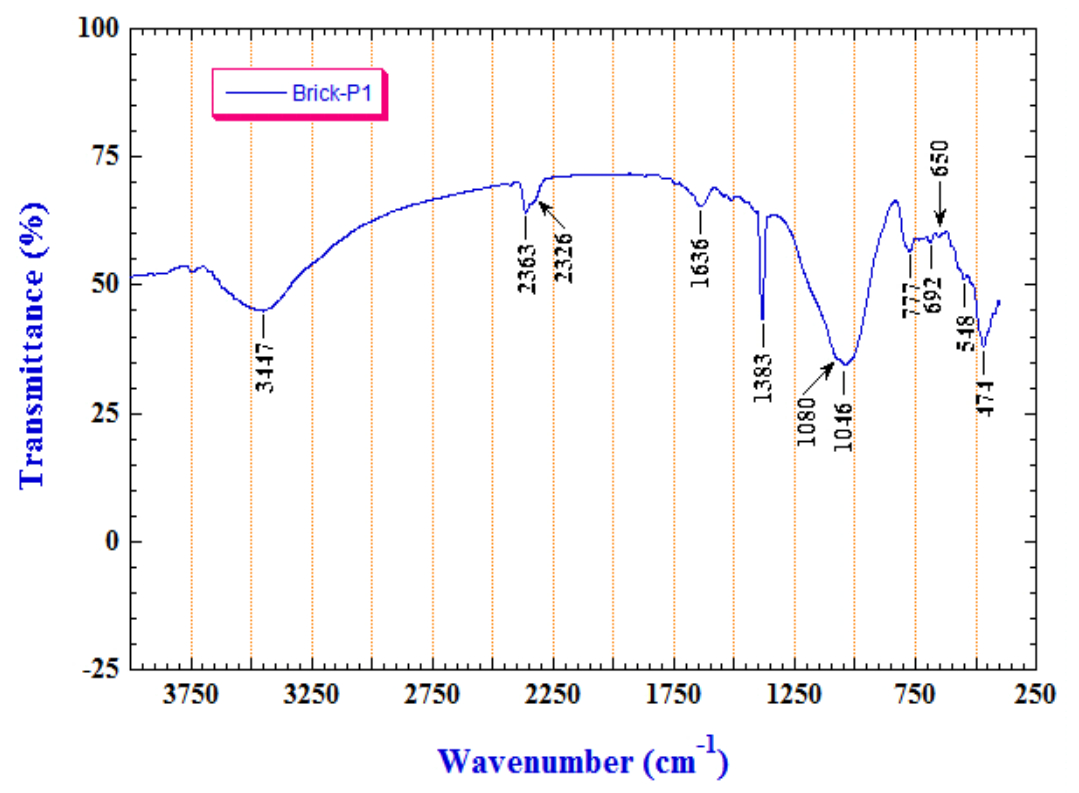

Figure5. FTIR spectra of clay brick-PI

In general, broadening of the FTIR spectra is also influenced the firing temperature range of the ceramic bodies like clay bricks, tiles and so on. Higher the firing temperature applied during the production of the clay bodies, more broadening of the FTIR spectra of the bodies at the region of the $\mathrm{OH}$ stretching vibration of hydroxide. It is clearly observed that the degree of broadening of the FTIR spectrum at the absorption band at $3441-3447 \mathrm{~cm}^{-1}$ is almost same for all three clay brick samples used to analyze in this study as shown in Figs 5-7. This absorption band region is always accompanied by an absorption band at $1630-1636 \mathrm{~cm}^{-1}$ assigned to $\mathrm{H}-\mathrm{O}-\mathrm{H}$ bending of adsorbed water molecules. In addition, there is a strong FTIR absorption peak at $1383 \mathrm{~cm}^{-1}$ for two brick samples of Brick-P1 and Brick-P3 as shown in Figs 5 and 7, respectively. However, the absorption peak at 1383 $\mathrm{cm}^{-1}$ region is not observed for the Brick-P2 sample, although the Brick-P2 have the absorption peak at $1871 \mathrm{~cm}^{-1}$ as shown in Fig. 6 .

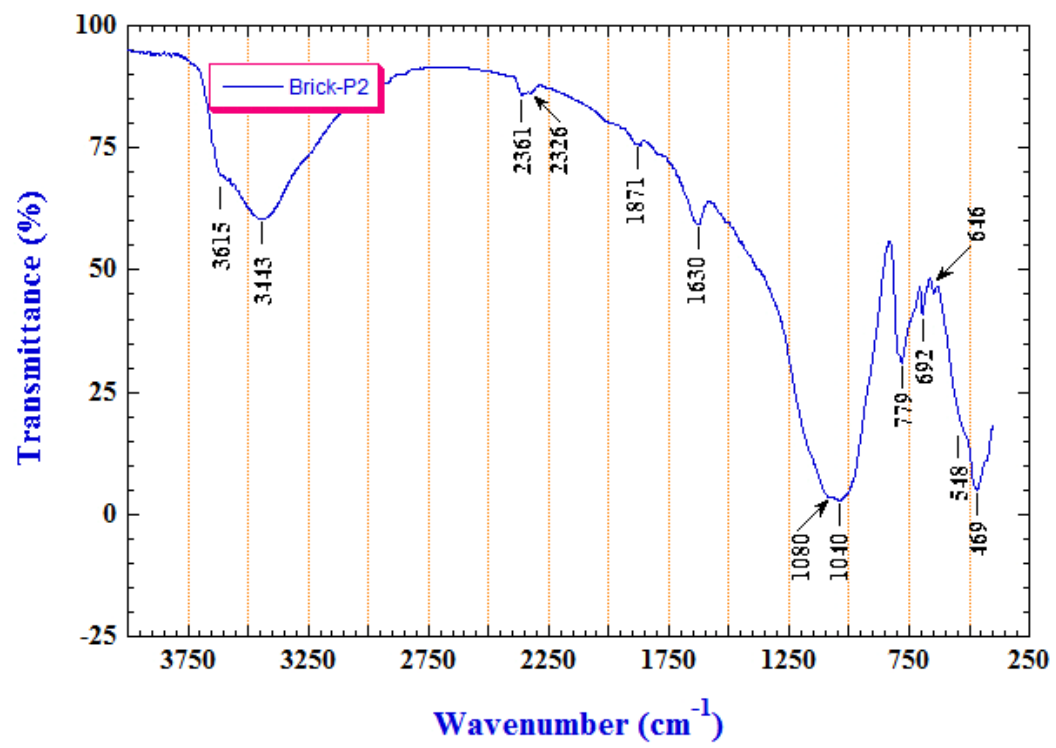

Figure6. FTIR spectra of clay brick-P2 
The FTIR absorption bands of clay minerals show $\mathrm{Si}-\mathrm{O}$ stretching and bending as well as $\mathrm{OH}$ bending absorptions in 1300-400 $\mathrm{cm}^{-1}$ range. Different arrangement within the layers $(1: 1$ versus $2: 1$ and/or di- versus tri-octahedral character) is reflected in the shape and positions of these absorption bands. The FTIR spectrum of all three clay brick samples analyzed in this study shows intensive band at $1028-1046 \mathrm{~cm}^{-1}$ attributed to the $\mathrm{Si}-\mathrm{O}$ stretching vibrations of the tetrahedral sheet of the clay raw minerals of the fired clay brick sample as shown in Figs 5-7. A weak absorption peak around 1080 $\mathrm{cm}^{-1}$ is present in the FTIR spectra of all the measured fired clay brick samples used in this study, which represents the presence of silica (Si-O stretching) in the brick samples. None of the clay brick samples analyzed in the present study showed the FTIR absorption bands at $940 \mathrm{~cm}^{-1}$ and $918 \mathrm{~cm}^{-1}$ implying that all the brick samples used in the present study should be fired at high temperature, more than $600^{\circ} \mathrm{C}$. It is meaningful for mentioning that the $\mathrm{O}-\mathrm{H}$ deformation vibrational modes were separated into two bands at 940 and $918 \mathrm{~cm}^{-1}$ which arise from intersheet and intrasheet hydroxyls which begin to disappear with increasing firing temperature [30]; [31] and hence it was reported that the FTIR absorption band at $921 \mathrm{~cm}^{-1}$ for the pillared-montmorillonite and beidellite was disappeared with increasing the firing temperature at above $600^{\circ} \mathrm{C}[26]$.

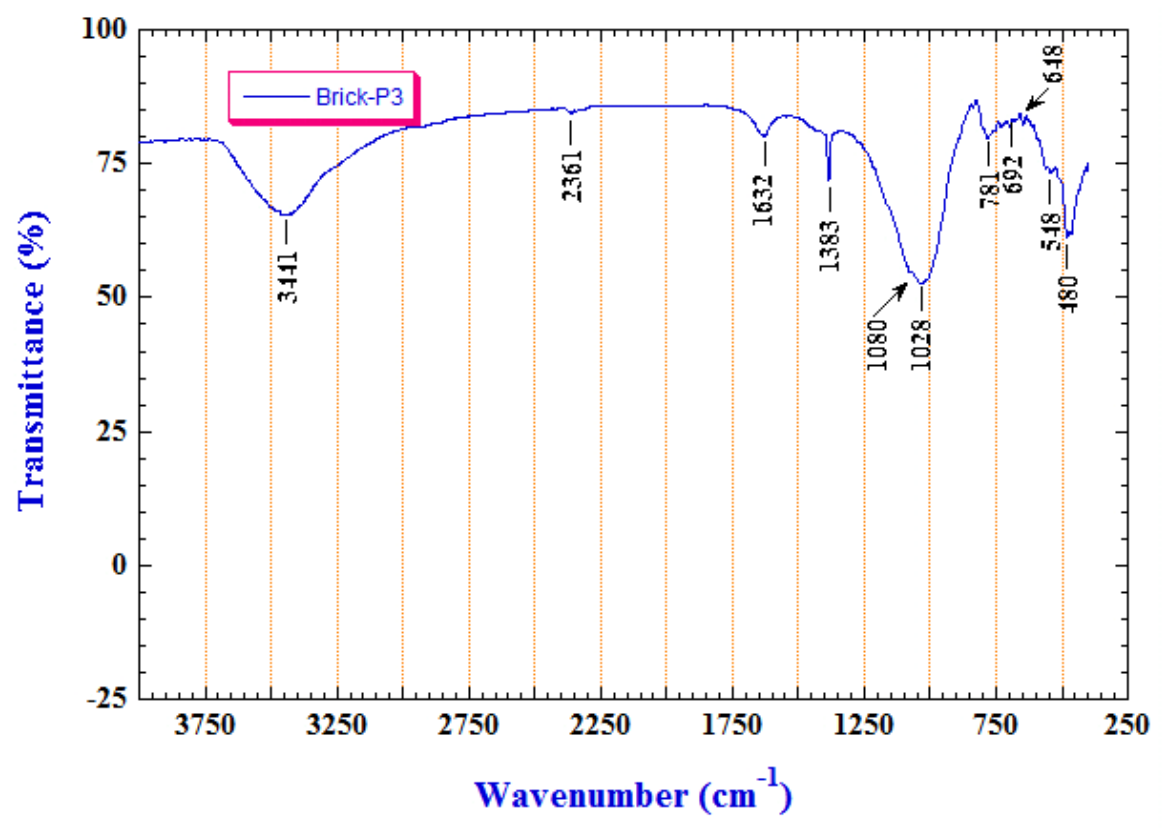

Figure7. FTIR spectra of clay brick-P3

The FTIR absorption bands at 548 and $469-480 \mathrm{~cm}^{-1}$ are assigned to $\mathrm{Si}-\mathrm{O}-\mathrm{Al}$ (octahedral $\mathrm{Al}$ ) and $\mathrm{Si}-$ $\mathrm{O}-\mathrm{Si}$ bending vibrations, respectively. The broadening of the absorption band at $548 \mathrm{~cm}^{-1}$ (Si-O bending peak) was seen due to the disorder of the octahedral sheet and the broadening of the Si-O stretching bands in the $1100-1000 \mathrm{~cm}^{-1}$ region was reported due to the disorder of the tetrahedral sheet [32]. The FTIR spectra of all these fired clay brick samples show that they are mainly composed of quartz (779-781, 692 and $\left.469-480 \mathrm{~cm}^{-1}\right)$. It is meaningful for mentioning here that previous research work reported a FTIR absorption peak chosen at around $779 \mathrm{~cm}^{-1}$ to be more suitable for qualitative amount of quartz in clay bodies [33]. On the other hand, the presence of feldspar can be explained by $\mathrm{Si}-\mathrm{O}-\mathrm{Al}$ compounded vibrations at $775-780 \mathrm{~cm}^{-1}$. These assignments are in good agreement with that previously reported for quartz and feldspar [34]. The absorption band at 779-781 $\mathrm{cm}^{-1}$, which is a complementary peak of $800 \mathrm{~cm}^{-1}$ band, is attributed to the presence of quartz [35]. In the present work, quartz is identified as predominant and makes the clay self-tempered during firing at high temperature of clay raw materials to produce the clay brick samples.

\section{CONClusions}

Mineralogy phases present in the clay bricks are mainly composed of biotite, cristobalite, feldspars, muscovite, quartz, mullite and so on based on the XRD patterns and FTIR peaks analysis. The results of the mineralogical phases of the brick bodies reflect that their firing temperature should be almost same over the kiln. It can be assumed that the disappearance of diffraction peaks for feldspars and appearance of mullite peaks in all three clay brick samples used in this study indicated that the firing temperature of these bricks should be more than $1100^{\circ} \mathrm{C}$. 


\section{ACKNOWLEDGEMENTS}

Author would like to express his sincere gratitude to Prof. Dr. Jagadeesh Bhattarai of Central Department of Chemistry, Tribhuvan University for his fruitful suggestions to conduct this research work and corrections of this manuscript. Mr. Dol Bahadure Gale is also acknowledged for his help to carry out the XRD and FTIR measurements at NAST.

\section{REFERENCES}

[1] Mohan, N. V., Satyanarayana, P. V. V. and Rao, K. S., Performance of rice husk ash bricks, International Journal of Engineering Research and Applications, 2(5), pp 1906-1910 (2012).

[2] Ahmari, S. and Zhang, L., Production of eco-friendly bricks from copper mine tailings through geopolymerization, Construction and Building Materials, 29, pp 323-331 (2012).

[3] Zhang, L., Production of bricks from waste materials- a review, Construction and Building Materials, 47, pp 643-655 (2014).

[4] Cultrone, G., Rodriguez-Navarro, C., Sebastian, E., Cazalla, O. and La Torre, M. J. D., Carbonate and silicate phase reactions during ceramic firing, European Journal of Mineralogy, 13, pp 621-634 (2001).

[5] Alves, H. J., Melchiades, F. G. and Boschi, A. O., Effect of feldspar particle size on the porous microstructure and stain resistance of polished porcelain tiles, Journal of the European Ceramic Society, 32, pp 2095-2102 (2012).

[6] Aduda, B. O. and Nyongesa, F. W., Role of aspect ratio in elastic modulus-porosity relationship of triaxial porcelain. British Ceramic Transactions, 99, pp 206-211 (2000).

[7] Pickup, R., Effect of porosity on Young's modulus of porcelain, British Ceramic Transactions, 96, pp 9698 (1997).

[8] Andreola, F., Leonelli, C., Romagnoli, M. and Miselli, P., Techniques used to determine porosity. American Ceramic Society Bulletin, 79, pp 49-52 (2000).

[9] Paudyal G., Assessment of ceramic wall tiles and bricks available in local market of Kathmandu valley and their characterization, M. Sc. Project work, Central Department of Chemistry, Tribhuvan University, Kirtipur, Nepal (2016)

[10] Budhathoki, P., Investigation on the physical, chemical, sintering and mechanical properties of ceramic tiles available in Kathmandu valley, M. Sc. Dissertation, Department of Chemistry, Tri-Chandra M. Campus, Tribhuvan University, Kathmandu, Nepal (2017)

[11] Bhattarai, J., Investigation on the physico-chemical and sintering properties of ceramic tiles and bricks available in local market of Kathmandu valley, UGC Faculty Research Gants-2072/73, University Grants Commission-Nepal, Sanothimi, Bhaktapur, Nepal

[12] Chung F. H. and Smith D. K., A Hand Book of Industrial Applications of X-ray Diffraction, edit Marcel Dekker, Inc., New York (1974)

[13] Berry I. G., Selected Powder Diffraction Data for Mineralogy, Joint Committee on Powdered Diffraction Standard, Swanshmore, USA (1974)

[14] El Nouhy, H. A., Assessment of some locally produced Egyptian ceramic wall tiles, Housing and Building National Research Center Journal, 9, 201-209 (2013)

[15] JCPDS, Joint Committee on Powder Diffraction Standards (1999)

[16] Mesbah, H., Wilson, M. and Carter, M., The role of the kaolinlite-mullite reaction sequence in moisture mass gain in fired kaolinite, Advanced Science and Technology Journal, 68, pp 38-43 (2010)

[17] Navarro, C. R., Cultrone, G. , Navas, A. S. and Sebastian, E., TEM study of mullite growth after muscovite breakdown, American Mineralogy, 88, pp 713-724 (2003)

[18] Schneider, H., Schreuer, J. and Hildmann, B. Structure and properties of mullite - A review, Journal of the European Ceramic Society, 28(2), pp 329-344 (2008). doi:10.1016/j.jeurceramsoc.2007.03.017

[19] Sadik, C., El Amrani, I. E. and Albizane, A., Processing and characterization of alumina-mullite ceramics, Journal Asian Ceramic Societies, 2(4), 310-316 (2014). https://doi.org/10.1016/j.jascer.2014.07.006

[20] Cultrone, G., Sebastian, E. and de la Torre, M. J., Mineralogical and physical behavior of solid bricks with additives, Construction and Building Materials, 19, pp 39-48 (2005) doi:10.1016/j.conbuildmat.2004. 04.035

[21] Tite, M. S., Kilikoglou, V. and Vekinis, G., Strength, toughness and thermal shock resistance of ancient ceramics and their influence on technological choice, Archaeometry, 43, pp 301-324 (2001)

[22] Traore, K., Ouédraogo, G. V., Blanchart, P., Jernot, J. -P. and Gomina, M., Influence of calcite on the microstructure and mechanical properties of pottery ceramics obtained from a kaolinite-rich clay from Burkina Faso, Journal of the European Ceramic Society 27(2-3), pp 1677-1681(2007) https://doi.org/ 10.1016/j.jeurceramsoc.2006.04.147 
[23] Sokolár, R., Vodova, L., Grygarova, S., Štubňa, I. and Šín, P., Mechanical properties of ceramic bodies based on calcite waste, Ceramics International, 38(8), pp 6607-6612 (2012). https://doi.org/10.1016/ j.ceramint.2012.05.046

[24] Bogahawatta, V. T. L. and Poole, A. B., Strength porosity mullite content relationships for kaolinitic clay bodies containing lime additive, British Ceramic Transactions, 90, pp 184-189 (1991)

[25] Sveda, M., New look at mathematical relationships among physical properties of brick products, British Ceramic Transactions, 99, pp 181-186 (2000)

[26] Kloprogge, J. T., Booy, E., Jansen, J. B. H. and Geus, J. W., The effect of thermal treatment on the properties of hydroxy-Al and hydroxy-Ga pillared montmorillonite and beidellite, Clay Minerals, 29, pp 153-167(1994)

[27] Bantignies, J. L., Moulin, C. C. D. and Dexpert, H., Wettability contrasts in kaolinite and illite clays: characterization by infrared and X-ray absorption spectroscopy, Clays and Clay Mineralogy, 45 (2), pp 184-193 (1997)

[28] Madejova, J., FTIR techniques in clay mineral studies, Vibrational Spectroscopy, 31(1), 1-10 (2003) https://doi.org/10.1016/S0924-2031(02)00065-6

[29] Velraj, G., Janaki, K., Musthafa, A. M. and Palanivel, R., Spectroscopic and porosimetry studies to estimate the firing temperature of some archaeological pottery shreds from India, Applied Clay Science, 43(3-4), pp 303-307 (2009) https://doi.org/10.1016/j.clay.2008.09.005.

[30] Farmer, V. C., Transverse and longitudinal crystal modes associated with $\mathrm{OH}$ stretching vibrations in single crystals of kaolinite and dickite, Spectrochimic Acta Part A: Molecular and Biomolecular Spectroscopy, 56(5), pp 927-930 (2000) https://doi.org/10.1016/S1386-1425(99)00182-1

[31] Cheng, H., Liu, Q., Yang, J., Du, X. and Frost, R. L., The thermal behavior of kaolinite intercalation complexes-a review, Thermochimica Acta, 545, pp 1-13 (2012)

[32] Elsass, F. and Oliver, D., Infrared and electron spin resonance studies of clays representative of the sedimentary evolution of the basin of Autun, Clay Minerals, 13, pp 299-305 (1978)

[33] Reig, F. B., Gimeno Adelantado, J. V. and Moya Moreno, M. C. M., FTIR quantitative analysis of calcium carbonate (calcite) and silica (quartz) mixtures using the constant ratio method: application to geological samples, Talanta, 58, pp 811-821 (2002)

[34] Hlavay, J., Jonas, K., Elek, S. and Inczedy, J., Characterization of the particle size and the crystallinity of certain minerals by IR spectrophotometry and other instrumental methods-II; Investigations on quartz and feldspar, Clays and Clay Mineralogy, 26(2), pp 139-143 (1978)

[35] Ojima, J., Determining of crystalline silica in repairable dust samples by infrared spectrophotometry in the presence of interferences, Journal of Occupational Health, 45, pp 94-103 (2003)

Citation: S. Shrestha, "Mineralogical Study of Historical Bricks of Patan, Nepal Using XRD and FTIR Analysis", International Journal of Advanced Research in Chemical Science (IJARCS), vol. 4, no. 9, pp. 28-35, 2017. http://dx.doi.org/10.20431/2349-0403.0409004

Copyright: (C) 2017 Authors. This is an open-access article distributed under the terms of the Creative Commons Attribution License, which permits unrestricted use, distribution, and reproduction in any medium, provided the original author and source are credited. 